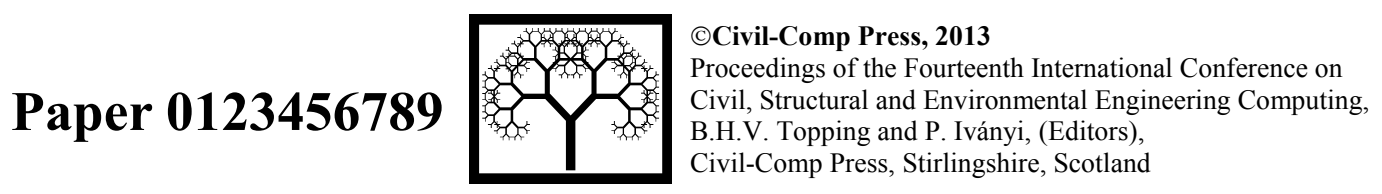

\title{
Limit Analysis of Loaded Out-of-Plane Rubble Masonry : A Case Study in Portugal
}

\author{
G. Milani ${ }^{1}$, Y.W. Esquivel ${ }^{2}$, P.B. Lourenço ${ }^{2}$, B. Riveiro ${ }^{3}$ and D.V. Oliveira ${ }^{2}$ \\ ${ }^{1}$ Department of Architecture, Built Environment \& Construction Engineering \\ Technical University of Milan, Italy \\ ${ }^{2}$ Department of Civil Engineering, University of Minho, Guimarães, Portugal \\ ${ }^{3}$ Department of Materials Engineering, Applied Mechanics \& Construction \\ University of Vigo, Spain
}

\begin{abstract}
An integrated methodology for the characterization of the response of rubble masonry is presented. The behaviour at collapse of a wall belonging to the Guimarães castle (Portugal) is investigated through a rigid-plastic homogenization procedure, accounting both for the actual disposition of the blocks constituting the walls and texture irregularity, given by the variability of block dimensions.

A detailed survey is conducted by means of a photogrammetric technique, allowing for a precise characterization of blocks dimensions and disposition. After a geometric simplification assuming mortar joints reduced to interfaces, homogenized masonry in- and out-of-plane strength domains are evaluated on a number of different representing elements of volume (RVEs) having different sizes and sampled on the walls of the castle. Strength domains are obtained using a finite element (FE) limit analysis with a heterogeneous discretization by triangles and interfaces.

Finally, a series of limit analyses are carried out on the façade for the safety assessment under seismic loads by means of two numerical models, the first one being a heterogeneous model and the second a homogenized approach. The reliability of the results, in terms of limit load and failure mechanism, provided by the homogenized model, when compared to the heterogeneous one is satisfactory.
\end{abstract}

Keywords: homogenization; quasi-periodic masonry; geometrical survey; limit analysis; structural safety, sampled RVEs.

\section{Introduction}

Masonry constituted by the assemblage of blocks with variable dimensions is very common in both existing and historical buildings in many countries. However, the complexity of the problem, and the number of variables required by accurate 
numerical heterogeneous FE analyses [1]-[3], usually preclude the study of these structures in the inelastic range through commercial software. As a consequence, it can be stated that, at present, the numerical analysis of masonry structures randomly assembled, remains a very challenging problem, despite the efforts recently expended by many authors to tackle the problem using stochastic homogenization schemes. In recent years, the interest in the conservation of historical buildings and in finding efficient numerical models, has led to a significant number of numerical model for historical masonry buildings, from very simple to complex ones [5]-[7], which are able to simulate the behaviour of the material under different type of loads. The choice depends on the degree of accuracy, sought in the analysis for each particular case.

The present paper deals with the characterization of the response of quasi-periodic masonry by means of a geometrical study and a statistical analysis of stone units, homogenization of masonry and structural implementation. For this purpose, it was decided: (a) to carry out the geometrical investigation of stones units from an existing case study (Guimarães castle), to obtain statistical parameters and distribution of the height and length of the stones units, with the aim of determining the adequate size of the representative volume elements; (b) to perform a homogenized limit analysis on a number of representative volume elements (RVEs) to obtain their in-plane and out-of-plane failure surfaces; (c) to carry out a series of structural limit analyses under static horizontal loads up to collapse of one of the walls (Alcaçova) and to compare limit loads and failure mechanisms provided by the homogenized model with those obtained by means of a detailed heterogeneous model, in order to check the reliability of the approach proposed and its applicability for practical purposes.

\section{Masonry homogenization: a brief state-of-the-art}

Homogenization theory may represent a powerful tool in problems involving periodic arrangements of heterogeneous materials, where the study of the whole structure within a heterogeneous approach is impractical or impossible, due to the computational effort. A non-rigorous homogenization may be also attempted for random composites, provided that a suitable portion of the whole structure (test window) is extracted.

The basic idea of homogenization [4] [6] consists in introducing averaged quantities representing the macroscopic strain and stress tensors (respectively $\boldsymbol{\Sigma}$ and $\mathbf{E}$ ) as follows:

$$
\mathbf{E}=<\boldsymbol{\varepsilon}>=\frac{1}{A} \int_{Y} \boldsymbol{\varepsilon}(\mathbf{u}) d Y \quad \boldsymbol{\Sigma}=<\boldsymbol{\sigma}>=\frac{1}{A} \int_{Y} \boldsymbol{\sigma} d Y
$$

where $A$ stands for the area of the elementary cell, $\boldsymbol{\varepsilon}$ and $\boldsymbol{\sigma}$ stand for the local quantities (stresses and strains respectively) and $\langle *\rangle$ is the averaging operator.

Periodicity conditions are imposed on the stress field $\boldsymbol{\sigma}$ and the displacement field u, given by: 
$\left\{\begin{array}{l}\mathbf{u}=\mathbf{E} \mathbf{y}+\mathbf{u}^{\text {per }} \quad \mathbf{u}^{\text {per }} \text { on } \partial Y \\ \boldsymbol{\sigma n} \text { anti - periodic on } \partial Y\end{array}\right.$

where $\mathbf{u}$ is the total displacement field and $\mathbf{u}^{\text {per }}$ stands for a periodic displacement. Here, it is worth noting that, in equation ( 2 ), the periodicity of the displacement fluctuation $\mathbf{u}^{\text {per }}$ forces corresponding boundary segments to exhibit the same shape in the deformed configuration.

Let $S^{\mathrm{m}}, S^{\mathrm{b}}$ and $S^{\text {hom }}$ denote respectively the strength domains of mortar, blocks and homogenised macroscopic material. It has been shown that a kinematic upper bound approximation of $S^{\text {hom }}$ can be derived through the support function $\pi^{\text {hom }}(\mathbf{D})$ as follows (see also [6] for further details):

$$
S^{\text {hom }}=\left\{\sum \mid\left\{\begin{array}{c}
\sum: \mathbf{D} \leq \pi^{\text {hom }}(\mathbf{D}) \quad \forall \mathbf{D} \in R^{6} \\
\pi^{\text {hom }}(\mathbf{D})=\inf _{\mathbf{v}}\left\{P(\mathbf{v}) \mid \mathbf{D}=\frac{1}{2 \Gamma} \int_{\partial Y=\Gamma}(\mathbf{v} \otimes \mathbf{n}+\mathbf{n} \otimes \mathbf{v}) d S\right\} \\
P(\mathbf{v})=\int_{Y} \pi(\mathbf{d}) d Y+\int_{S} \pi([[\mathbf{v}]] ; \mathbf{n}) d S
\end{array}\right\}\right.
$$

where:

- $\mathbf{v}=\mathbf{D} \mathbf{y}+\mathbf{v}^{\mathrm{per}}$ is the microscopic velocity field;

- $\quad \mathbf{v}^{\text {per }}$ is a periodic velocity field;

- $\mathbf{d}$ and $\mathbf{D}$ are respectively the microscopic and macroscopic strain rate fields;

- $S$ is any discontinuity surface of $v$ in $Y$, $\mathbf{n}$ is the normal to $S$;

- $\quad \pi([[\mathbf{v}]] ; \mathbf{n})=1 / 2([[\mathbf{v}]] \otimes \mathbf{n}+\mathbf{n} \otimes[[\mathbf{v}]]) ;$

- $\pi(\mathbf{d})=\max _{\boldsymbol{\sigma}}\{\boldsymbol{\sigma}: \mathbf{d} ; \boldsymbol{\sigma} \in S(\mathbf{y})\}$.

The above considerations hold on a Representative Element of Volume (REV) that should generate the entire wall by repetition. The REV is defined as the smallest volume that contains all the essential information about the microstructure. On the boundaries of the REV, periodicity and anti-periodicity conditions should be assigned in agreement with equation ( 2 ).

However, the identification of a REV for old masonry is not always an easy task, as is the case here analysed. The most straightforward approach is represented by large sampling of several REVs with different dimensions in different positions of the wall under study and in the average evaluation of their ultimate behaviour, both for in-plane loads under different directions of the load with respect to the bed joint [8] and their flexural response, as detailed in [9].

\section{Guimarães castle: geometry of the masonry units}

The origin of the castle dates back to the $10^{\text {th }}$ century and the fights against the Moors in the Iberian Peninsula. In the $11^{\text {th }}$ century, the first King of Portugal was born there. Later, between the $12^{\text {th }}$ and $14^{\text {th }}$ centuries, the castle was enlarged and the defence capacity was improved. At a certain stage, the castle was abandoned and 
suffered damage caused by time, and by the subsequent changes of use. In the $20^{\text {th }}$ century, important restoration works have been carried out. The current condition is shown in Figure 1, where the pentagonal plan view of the castle is reported. The castle is surrounded by eight square towers, which delimit the main square, with a main tower ("Torre de Menagem" in Portuguese and "Keep" in English) in the centre. The main wall under study in this paper is the so-called "Alcáçova" Wall, which is originally the highest and most protected part of an Iberian medieval castle, with a defence function and where the civil or ecclesiastical authorities lived. The word was later used to define the part of the castle where the governor lived.

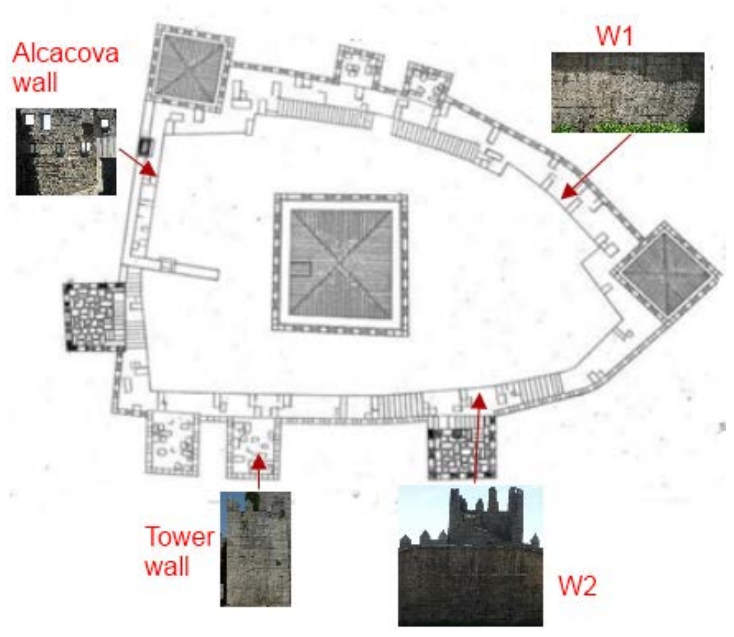

(a)

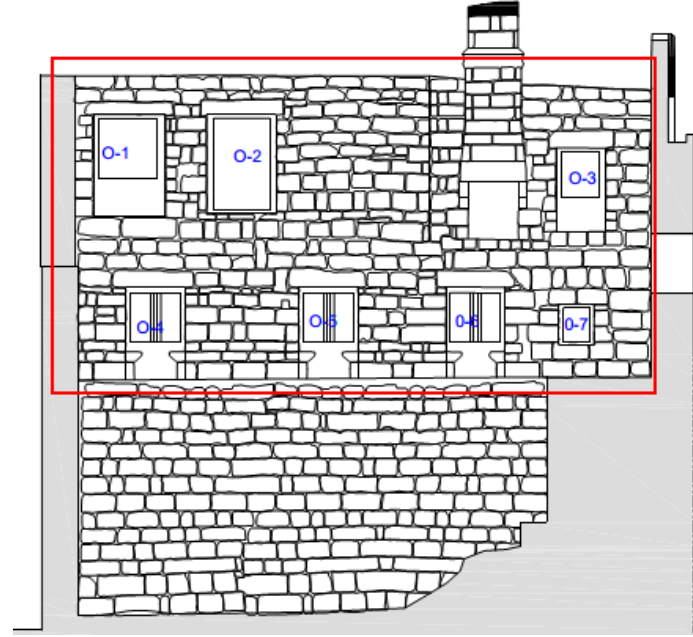

(b)

Figure 1: Castle of Guimarães: a) Plan view and (b) “Alcáçova” wall

The masonry of the castle is made using granite stone ashlars in the external leaves. The masonry features horizontal courses and is relatively regular, despite the fact that the height of the courses is not constant and that the length of the units is rather variable. In order to represent this feature, a statistical description considering mean, standard deviation, coefficient of variation and probability distribution of the size of the stone units from four walls was made: Wall1, Wall2, Tower wall and Alcaçova wall, see Figure 2 and Table 1. The walls were analysed separately and together as a single group. The objective was to characterize the length $l$ and height $h$ of stone units and the results are shown in Table 1 . The procedure was to identify the stone units in a first step and then to define the best fit probabilistic distribution, which is a lognormal (skew) distribution for both variables.

The following aspects from the geometric data are relevant: (a) there is a large variation between the mean value of the stone length and height in the four walls selected for sampling ( 0.60 to $0.85 \mathrm{~m}$ in length and 0.34 to $0.46 \mathrm{~m}$ in height). The ratio between the maximum and minimum averages in the different samples is similar in length and height (about 75\%); (b) the stone geometrical ratio is rather important for the quality of the masonry bond. The value of $h / l$ for the average geometrical dimensions is about 56\% (1:1.8). Only in Wall2, a slightly different $h / l$ ratio is found, equal to $63 \%(1: 1.6)$; (c) the scatter found in the length is always 
much larger than the scatter found in the height, being the scatter in the full sample not so much different from the scatter in the individual samples; (d) wall 2 is the sample with the lowest scatter and the Alcaçova is the sample with the largest scatter, despite the fact that the Alcaçova sample is three times larger than Wall 2; (e) the difference between averaging the total sample weighted by the number of samples or weighted equally is only moderate, with about $5 \%$ change in the dimensions; (f) the probabilistic distribution for the length is clearly skewed, requiring a lognormal distribution. The probabilistic distribution for the height is symmetric, meaning that a normal distribution can be used.

\begin{tabular}{|c|c|c|c|c|c|c|c|c|}
\hline \multirow[b]{2}{*}{$\begin{array}{l}\text { Results } \\
\text { Wall }\end{array}$} & \multirow[b]{2}{*}{$\begin{array}{l}\text { Number of } \\
\text { units }\end{array}$} & \multirow{2}{*}{$\begin{array}{c}\text { Ratio } \\
\text { Height } \\
/ \\
\text { Length } \\
h / l \\
\end{array}$} & \multicolumn{3}{|c|}{ Length } & \multicolumn{3}{|c|}{ Height } \\
\hline & & & $\begin{array}{c}\text { Average } \\
{[\mathrm{m}]} \\
(\mathrm{CoV})\end{array}$ & $\begin{array}{l}\text { Typical [m] } \\
\text { (Frequency) }\end{array}$ & $\begin{array}{l}\text { Range } \\
{[\mathrm{m}]}\end{array}$ & $\begin{array}{l}\text { Height [m] } \\
(\mathrm{CoV})\end{array}$ & $\begin{array}{c}\text { Typical [m] } \\
\text { (Frequency } \\
\text { ) }\end{array}$ & $\begin{array}{c}\text { Range } \\
{[\mathrm{m}]}\end{array}$ \\
\hline $\begin{array}{l}\text { Wall } \\
\text { W1 }\end{array}$ & 110 & 0.51 & $\begin{array}{c}0.76 \\
(34 \%)\end{array}$ & $\begin{array}{c}0.70 \\
(27 \%)\end{array}$ & $\begin{array}{l}0.40- \\
1.70\end{array}$ & $\begin{array}{c}0.39 \\
(20 \%)\end{array}$ & $\begin{array}{c}0.40 \\
(38 \%)\end{array}$ & $\begin{array}{c}0.20- \\
0.40\end{array}$ \\
\hline $\begin{array}{l}\text { Wall } \\
\text { W2 }\end{array}$ & 110 & 0.63 & $\begin{array}{c}0.70 \\
(27 \%)\end{array}$ & $\begin{array}{c}0.65 \\
(27 \%)\end{array}$ & $\begin{array}{l}0.45- \\
1.35\end{array}$ & $\begin{array}{c}0.44 \\
(19 \%)\end{array}$ & $\begin{array}{c}0.40 \\
(25 \%)\end{array}$ & $\begin{array}{c}0.25- \\
0.60\end{array}$ \\
\hline Tower & 110 & 0.54 & $\begin{array}{c}0.85 \\
(37 \%)\end{array}$ & $\begin{array}{c}0.65 \\
(34 \%)\end{array}$ & $\begin{array}{l}0.50- \\
1.80\end{array}$ & $\begin{array}{c}0.46 \\
(17 \%)\end{array}$ & $\begin{array}{c}0.50 \\
(35 \%)\end{array}$ & $\begin{array}{c}0.15- \\
0.60\end{array}$ \\
\hline $\begin{array}{c}\text { Alcaçov } \\
\mathrm{a}\end{array}$ & 308 & 0.56 & $\begin{array}{c}0.60 \\
(44 \%)\end{array}$ & $\begin{array}{c}0.45 \\
(25 \%)\end{array}$ & $\begin{array}{l}0.25- \\
2.10\end{array}$ & $\begin{array}{c}0.34 \\
(23 \%)\end{array}$ & $\begin{array}{c}0.40 \\
(35 \%)\end{array}$ & $\begin{array}{l}0.15- \\
0.60\end{array}$ \\
\hline $\begin{array}{c}\text { Full } \\
\text { Sample }\end{array}$ & $\begin{array}{c}\text { Weighted } \\
\text { average }\end{array}$ & 0.56 & $\begin{array}{c}0.69 \\
(40 \%)\end{array}$ & $\begin{array}{c}0.55 / 0.65 \\
(21 \%) /(20 \%)\end{array}$ & $\begin{array}{c}0.25- \\
2.10\end{array}$ & $\begin{array}{c}0.38 \\
(24 \%)\end{array}$ & $\begin{array}{c}0.40 \\
(35 \%)\end{array}$ & $\begin{array}{c}0.15- \\
0.60\end{array}$ \\
\hline
\end{tabular}

Table 1: Geometric Data Measured

\section{Homogenized limit analysis of RVEs}

Next, a study on different representative volume element (RVE) samples from the Alcaçova wall is presented. The RVEs are firstly analysed under in-plane load in order to obtain membrane failure surfaces at different orientations of a load with respect to the bed joint, considering masonry with weak and strong mortar joints, aiming at representing a possible injection intervention. The RVEs are also analysed under out-of-plane load in order to obtain the out-of-plane surface failure at increasing compressive loads. The result allows subsequent implementation of the obtained failure surfaces in the study of the full masonry wall. In-plane failure surfaces are described by horizontal strength $\left(\sigma_{h}\right)$ and vertical strength $\left(\sigma_{v}\right)$. Out-ofplane failure surfaces are described by horizontal bending moment $\left(M_{11}\right)$, vertical bending moment $\left(M_{22}\right)$ and torsional moment, or torsion $\left(M_{12}\right)$. 


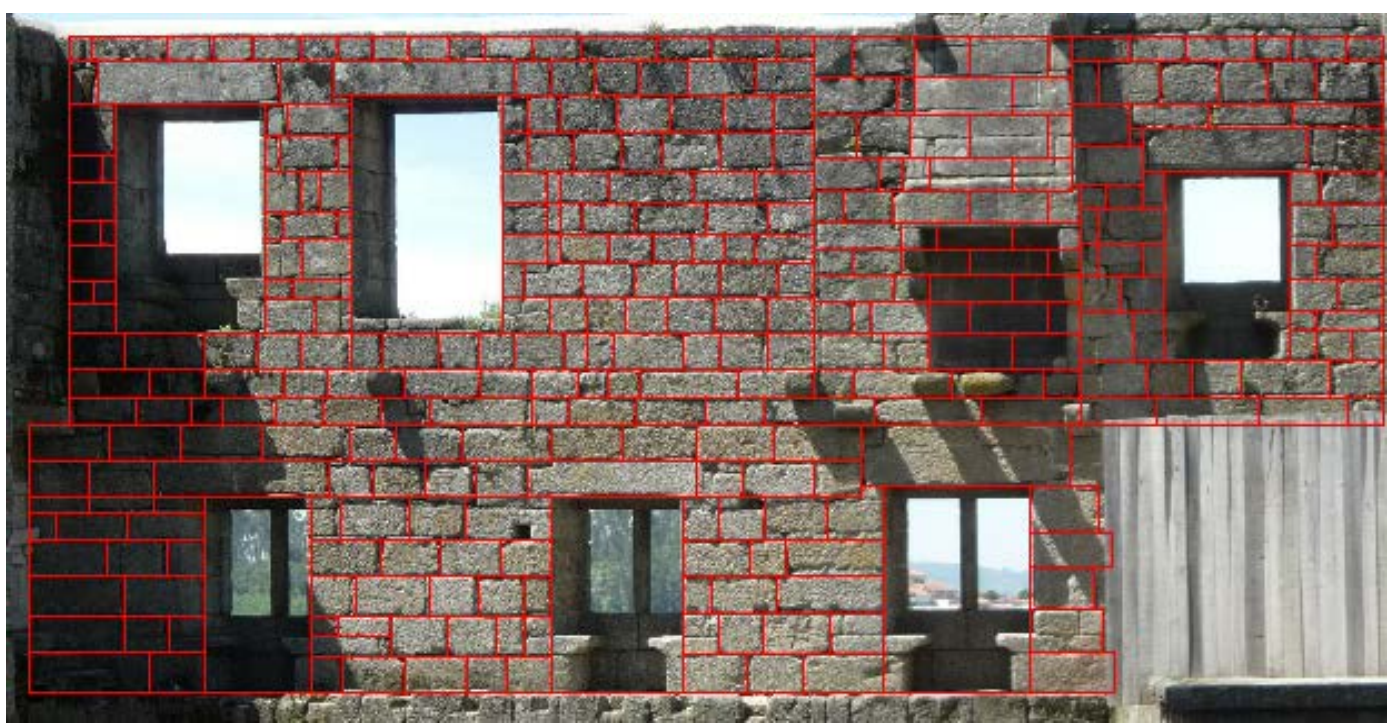

(a)
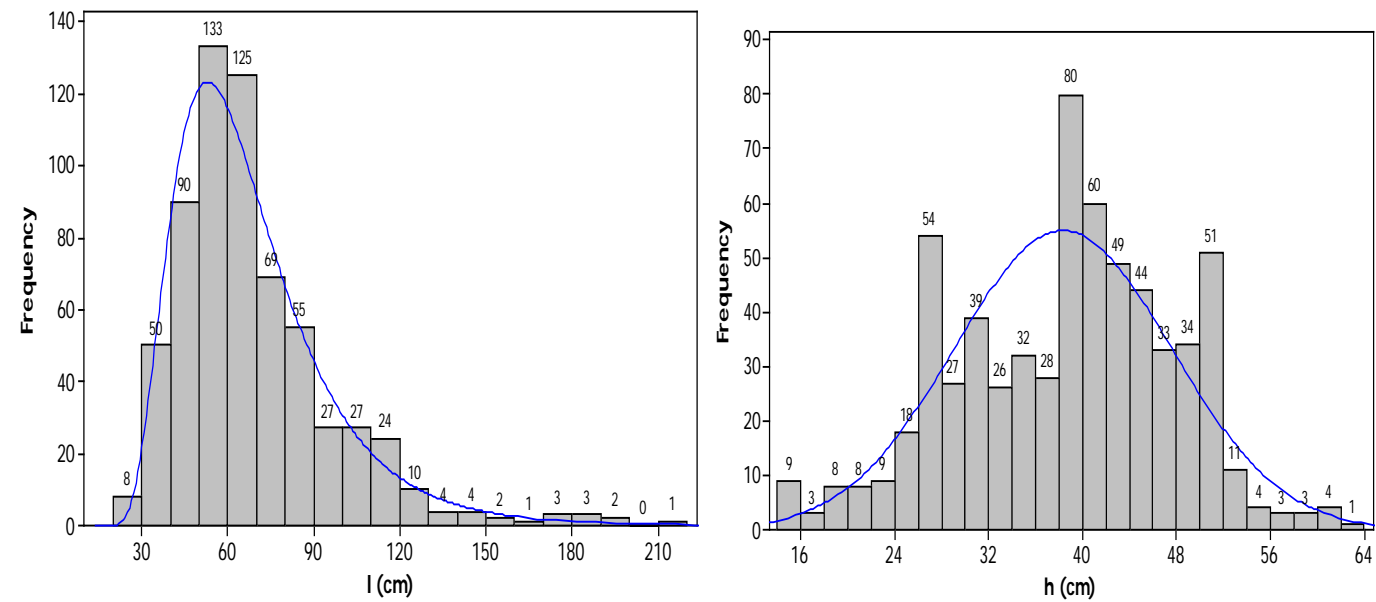

(b)

Figure 2: Geometric Survey of the Units: (a) Identification in the Alcaçova Wall; (b) Distribution of Length $(l)$ and Height $(h)$ in the Entire Sample

The Alcáçova wall is built using two external leaves with an average thickness of $400 \mathrm{~mm}$, separated by an infill. It was decided to consider three RVEs of different size: the first size, called $3 \times 3$, has dimensions three times the mean width and the mean height of stone; the second size, called $4 \times 4$, is four times the mean width and the mean height of stone; and the third size, called $5 \times 5$, is fifth times the mean width and the mean height of stone. For each size of RVE, three different samples located randomly on the wall are taken into account, as schematically represented in Figure 3. In addition, three artificial RVEs were built using mean size stones and periodic arrangement in order to compare the failure surfaces between the RVEs with quasi periodic arrangement and the RVEs with periodic arrangement using average geometry. A linearized Lourenço and Rots [5] failure criterion is adopted for joints reduced to interfaces and a classic Mohr-Coulomb failure criterion is used for brick interfaces, as in [1][9]. 


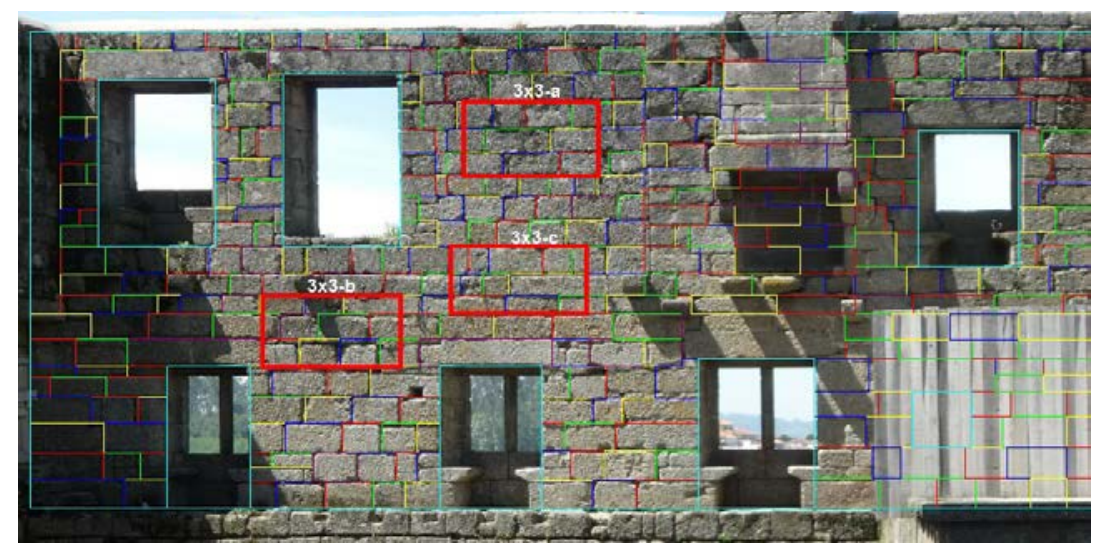

Figure 3: Location of 3x3 Representative Volume Elements (RVEs)

The in-plane homogenized failure surfaces $\left(\sigma_{v}-\sigma_{h}\right)$ are obtained keeping a $\vartheta$ angle fixed. This angle measures the rotation of the principal stresses with respect to the material axes. Three different $\vartheta$ angles are considered $\vartheta=0^{\circ}, \vartheta=22.5^{\circ}$ and $\vartheta=45^{\circ}$ (Figure 4-a) in analogy to [8][9]. For each RVE and in each orientation $\vartheta, 32$ values with steps of half of $22.5^{\circ}$ have been calculated. The 32 points were then connected to draw failure surfaces. The optimization problem arising in order to obtain the failure surface is solved by using an algorithm code developed in [6][9].

Different hypotheses on the mechanical properties of the mortar joints are investigated, simulating a scarcely resistant masonry (actual situation) and a strong material (hypothesis of rehabilitation with injection of mortar having good mechanical properties).

For masonry with weak mortar, the compressive strength of masonry is assumed equal to $12 \mathrm{MPa}$ and the ultimate tensile strength of joints is assumed equal to 0.05 $\mathrm{MPa}$. The compressive strength of stones is assumed equal to $89.5 \mathrm{MPa}$ and their ultimate tensile strength is equal to $0.93 \mathrm{MPa}$ [10][11]. For masonry with strong mortar, only the ultimate tensile strength of joints is changed, assuming a value equal to $0.3 \mathrm{MPa}$.

A full discussion and presentation of the results is provided in [12]. Here, for the sake of conciseness, only a small sample of the huge amount of experimental results obtained by the authors is reported.

Figure 4b shows typical in-plane homogenized failure surfaces for RVEs of masonry with weak mortar at different orientations of the load with respect to the bed joint. The usual anisotropic behaviour of masonry is found. Figure 4c shows a comparison between in-plane homogenized failure surfaces obtained from RVEs of the same size and artificial RVEs with periodic arrangement for masonry at a given orientation. Finally, Figure 4d shows a comparison between the mean values of inplane homogenized failure surfaces at a given orientation for all sizes of the RVEs, where it is shown that small difference are found. These results seem to indicate that the average of 3 masonry samples, with minimum size of 3x3, provides a reasonable estimate of the true failure surface. Further details on these results can be found in [11]. 


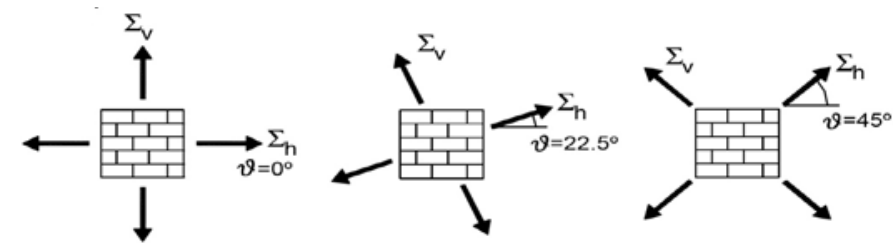

(a)

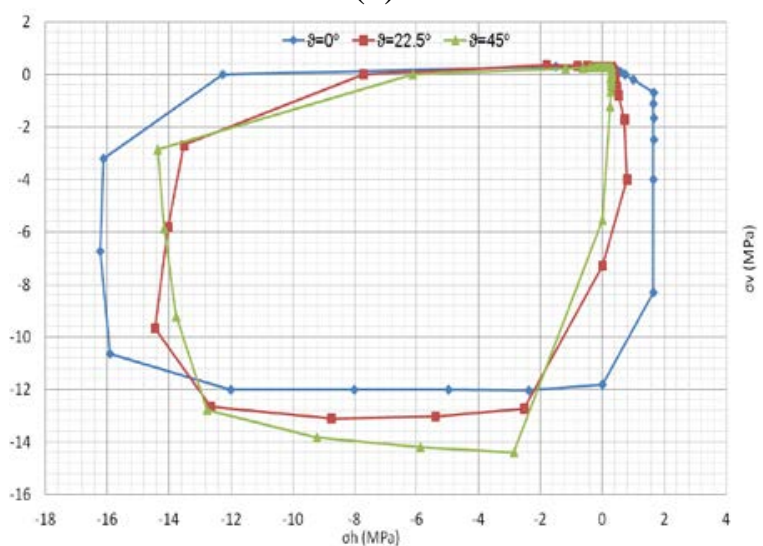

(b)

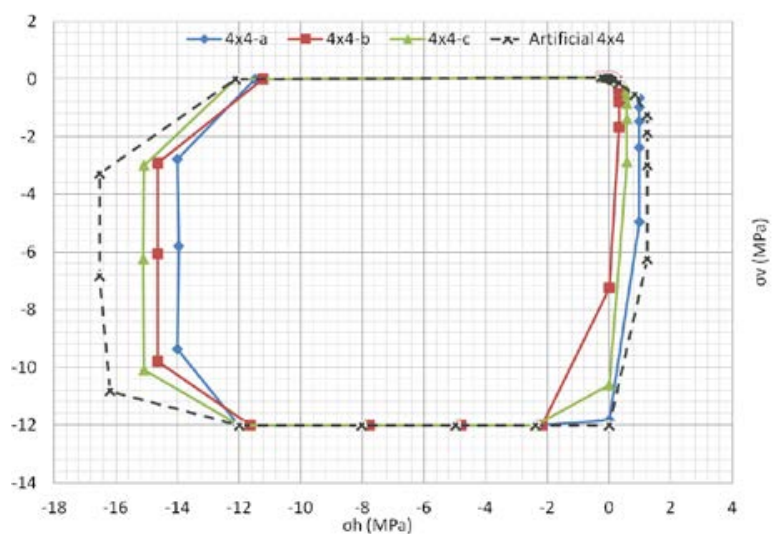

(c)

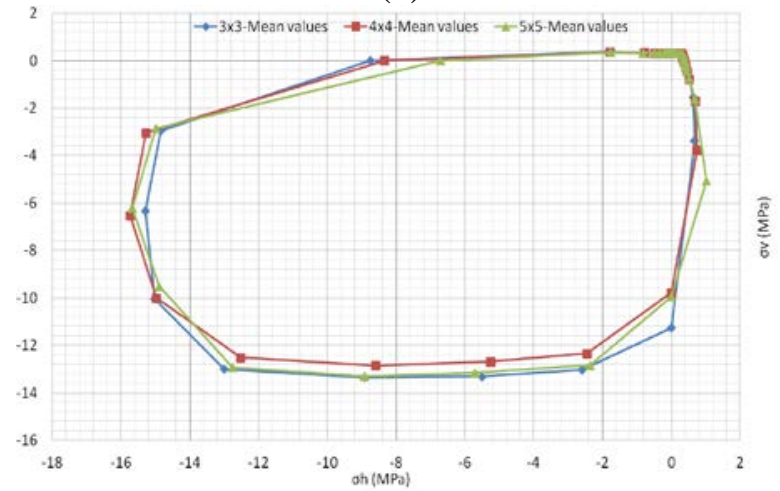

(d)

Figure 4: Homogenization: (a) $\vartheta$ angle orientations of the external load with respect to the bed joint; (b) example of a result with different orientations; (c) example of a result for different cells of the same size; (d) example of a result for cells of different size. 
Failure modes obtained from representative volume elements are depicted in Figure 5, where a qualitative comparison with experimental results [13] is also shown. A staircase crack in the $4 \times 4$ representative volume element is found independently of the quality of the mortar. It is noted that dilatancy is present in the numerical model, even if it is believed that the influence in the global behaviour is very low (the upper boundary is allowed to move up, meaning that an artificial confining stress built up does not occur).
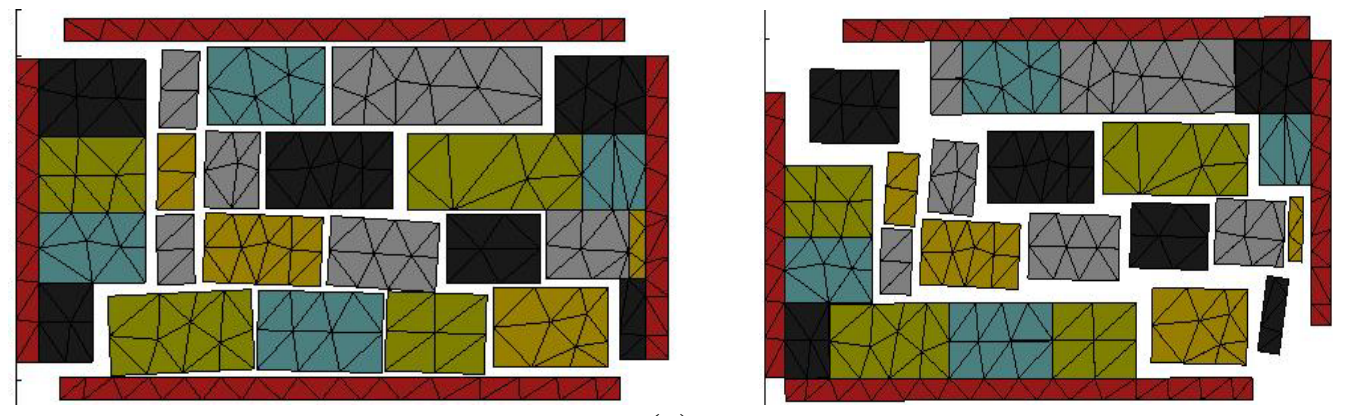

(a)
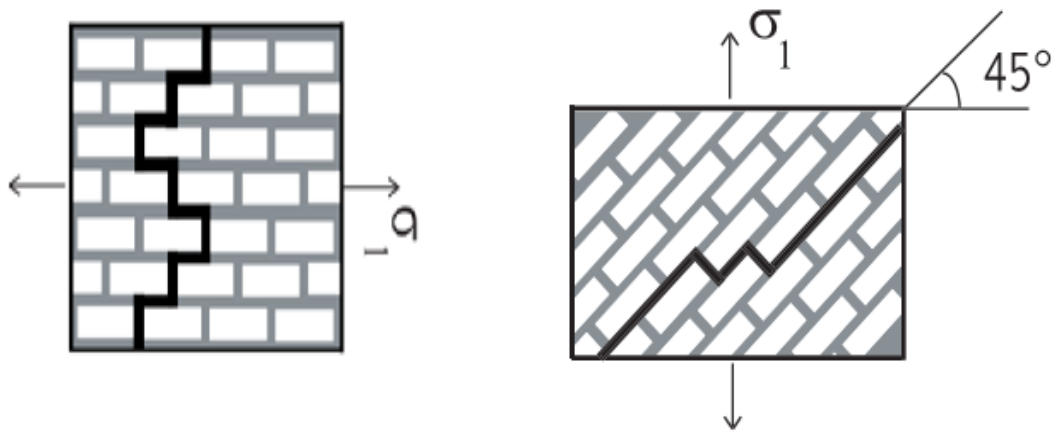

(b)

Figure 5: Qualitative comparison of mode failure between a masonry RVE with load orientations equal to $\vartheta=0^{\circ}$ and $45^{\circ}$ : (a) Numerical; (b) Experimental.

\section{Out-of-plane homogenized failure surfaces}

Out-of-plane loads are responsible for the majority of failures experienced in masonry structures, and especially in historical buildings, whose façades are usually characterized by a relative small thickness in comparison with height and length and a box behaviour is hardily present due to deformable floors. For this reason it is paramount to evaluate out-of-plane homogenized failure surfaces $\left(\mathrm{M}_{11}-\mathrm{M}_{22}\right.$ and $\mathrm{M}_{11^{-}}$ $\mathrm{M}_{12}$ ), which are obtained, similarly to the in-plane case, from a combination of homogenization techniques and limit analysis. Again, plasticity and associated flow rule for the constituent materials are assumed. The RVE is subdivided into 12 layers along the thickness (a conservative thickness is considered, assuming only the Alcaçova wall external leaf, with $h=400 \mathrm{~mm}$ ). For each layer, the out-of-plane components $\sigma_{i 3}(i=1,2,3)$ of the micro-stress tensor $\sigma$ are set to zero, meaning that 
only the in-plane components $\sigma_{i j}(i, j=1,2)$ are considered active and constant in the thickness.

The out-of-plane homogenized failure surfaces in sections in the space of bending moment $\left(M_{22}\right)$ and horizontal bending moment $\left(M_{11}\right)$ are generated from the integration of in-plane homogenized stress for which the algorithm requires the following data: RVE thickness, hereafter assumed equal to $0.40 \mathrm{~m}$; the number of layers in which the thickness of the RVE will be divided, selected as twelve layers; the compressive vertical load, which is considered at three different levels $N_{22}=0$ (top), $N_{22}=$ self-weight/2 (mid-height), $N_{22}=$ self-weight (bottom) of the Alcaçova wall; and the values of the in-plane failure surfaces. On the other hand ,for obtaining the out-of-plane homogenized failure surfaces in sections in the space of torsion $\left(M_{12}\right)$ and horizontal bending moment $\left(M_{11}\right)$, the algorithm requests the geometry of the mesh, number of elements and the properties of the masonry, using a process similar to the in-plane case.

Figure 6a shows out-of-plane homogenized failure surfaces $\left(\mathrm{M}_{11}-\mathrm{M}_{22}\right)$ for a sampled RVE at the three increasing vertical compressive loads previously discussed. As it can be seen, the vertical compression applied increases not only the horizontal bending moment $\left(M_{11}\right)$ but also the vertical bending $\left(M_{22}\right)$ and torsion $\left(M_{12}\right)$. This means that bed joints, in general, contribute to masonry vertical and torsion ultimate moment due to the friction effect of interlocking units. In some cases, due to insufficient staggering of the stones in the RVE with strong mortar, $M_{11}$ does not increase as a straight vertical crack is obtained. Figure 6b shows out-of-plane homogenized failure surfaces $\left(M_{11}-M_{12}\right)$ for RVEs of masonry with increasing vertical compressive loads. Again, the vertical compression load applied usually increases not only the horizontal bending moment but also the vertical bending moment $\left(M_{11}\right)$ and torsion $\left(M_{12}\right)$. Finally, Figure 6c shows a comparison between the mean values of out-of-plane homogenized failure surfaces of RVEs of the same size when the compressive load is maximum and equal to $N_{22}=133 \mathrm{kN} / \mathrm{m}$. As it can be observed, the vertical bending moment $\left(M_{22}\right)$ exhibits similar values for the different cell sizes (as well as the torsion $M_{12}$ ). The horizontal bending moment $\left(M_{11}\right)$ exhibits some scatter for the different average results, as it is more sensitive to the compressive loads. However, the scatter may be considered as moderate for engineering purposes.

\section{Limit analysis of the alcaçova wall of Guimarães castle}

The present study is focused in the part of the Alcaçova wall located above a much thicker panel, composed by two external leaves of stone masonry and an infill material in the middle, see Figure 4 . The wall is connected to secondary small buildings and rooms. The analysis of the whole wall would require full 3D computations, which are outside the scope of the present paper. Therefore, attention is devoted exclusively to the Alcaçova wall. 


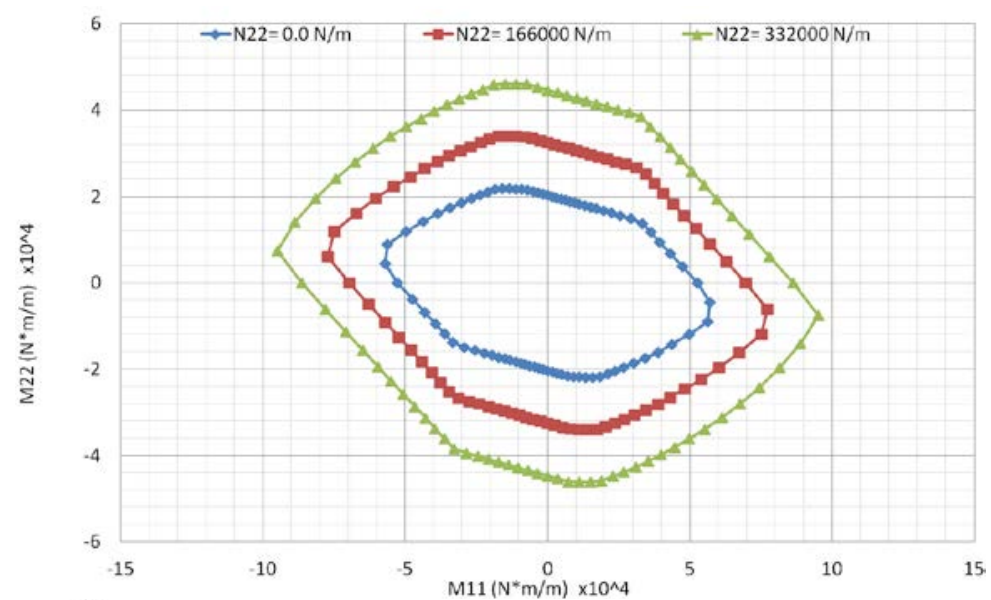

(a)

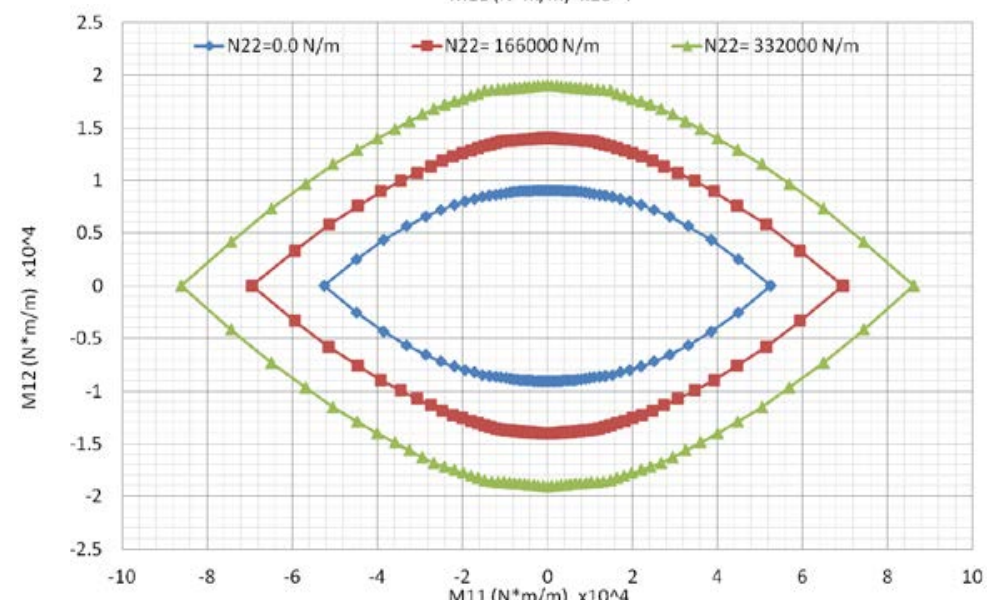

(b)

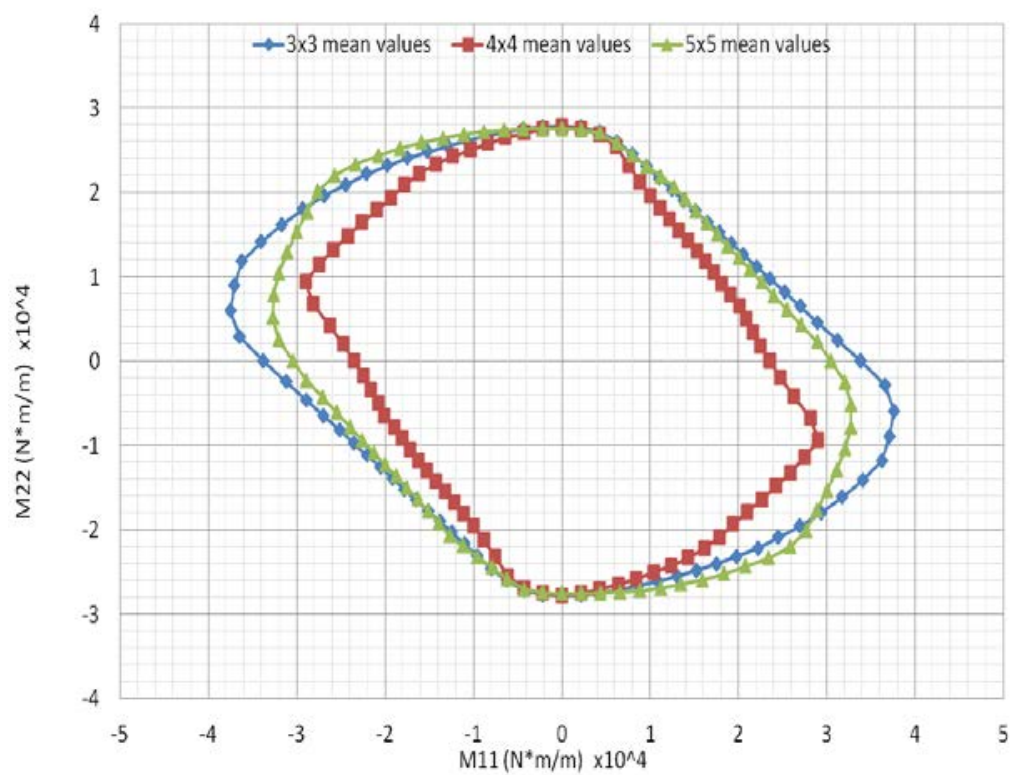

(c)

Figure 6: Results of out-of-plane homogenization: example of failure surfaces in (a) $\left(M_{11}-M_{22}\right)$ plane and in (b) $\left(M_{11}-M_{12}\right)$ plane for increasing vertical compression; (c) comparison between the mean values for different RVEs sizes. 
The portion of the wall under consideration may be reasonably assumed as supported on three edges, one corresponding to the lower edge, the remaining two corresponding to vertical boundaries. The dimensions of the wall are $14.25 \mathrm{~m}$ in length and $6.85 \mathrm{~m}$ in height. The thickness of the external leaves is $0.40 \mathrm{~m}$. The wall has seven openings, labelled from O-1 to O-7 for the sake of clearness in Figure 4. The openings represent approximately $20 \%$ of the area of the entire wall. Above each opening a lintel is present.

Two numerical models are utilized and the results obtained critically compared: the first is a heterogeneous model, where the actual disposition of the blocks is considered in detail, whereas the second is a homogenized model where strength domain obtained in the previous section are utilized.

Limit analyses are performed using the out-of-plane model utilized for e.g. in [9] , where plastic dissipation is allowed only at the interfaces between adjoining elements.

Results obtained comprise limit loads and the possible collapse mechanisms, whereas no information on displacements is provided. External seismic load depending on the load multiplier is applied to the model as out-of-plane pressure on single elements following a first mode distribution.

Collapse mechanism obtained by means of both the heterogeneous and the homogenized model assuming joints with weak mortar are depicted in Figure 7. The actual thickness of the plate elements is visualized for the sake of clearness, as well as all the cracks forming the failure mechanism are labelled.

Cracks a4, a5, a13, a14, a17 belong to two types of vertical cracks located in the middle third of the wall. These cracks are caused by the vertical bending moment. Crack a4 is a vertical line and forms for the inexistent staggering of the blocks in eleven masonry courses in this area. Crack a13 propagates following head and bed joints, whereas Cracks a8 and a18 follow the horizontal alignment of the blocks. Cracks a1, a2, a3, a6, a7, a9, a10, a11, a12, a15, a16 appear on corners and surrounding different portions of the openings, and are mainly diagonal, propagating for a combined effect of horizontal and vertical bending moment. This combination of effects is caused by the edge constrains applied to the wall, representing the connections of the Alcaçova wall with orthogonal walls and with the base horizontal base. It is important to remark that these types of cracks develop on areas close to the lateral edges. Finally, it can be stated that globally the failure mechanism is similar to a local overturning, as usually occurs for historical masonry buildings.

When dealing with the homogeneous model, it should be taken in to account that cracks can only follow the mesh lines. As can be seen from Figure 10, where the failure mechanism obtained by means of the homogenized model is represented, such model appears in term of cracks, in satisfactory agreement with the heterogeneous one. In particular, crack b1 is similar to a1, b2 to a2, b3 to a3. b4 appears slightly different and propagates on the right side, but maintaining the same pattern (vertical crack). b5 is again similar to a5, a6 to b6, b7 to a9, b8 to a11, b14 to a19, b15 to a14, b16 to b15, b17 to a16, b18 to a18 and b19 to a17. Cracks b10, b11, b12 and b20 exhibit some discrepancies. However, from a global point of view, the agreement seems quite satisfactory, both models providing comparable failure mechanisms. 


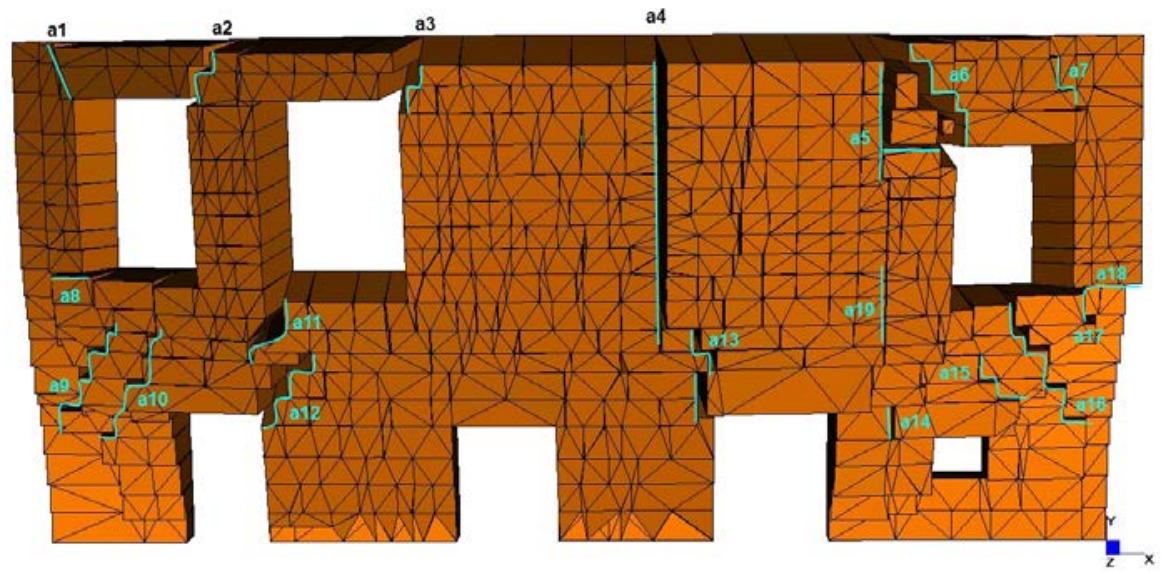

(a)

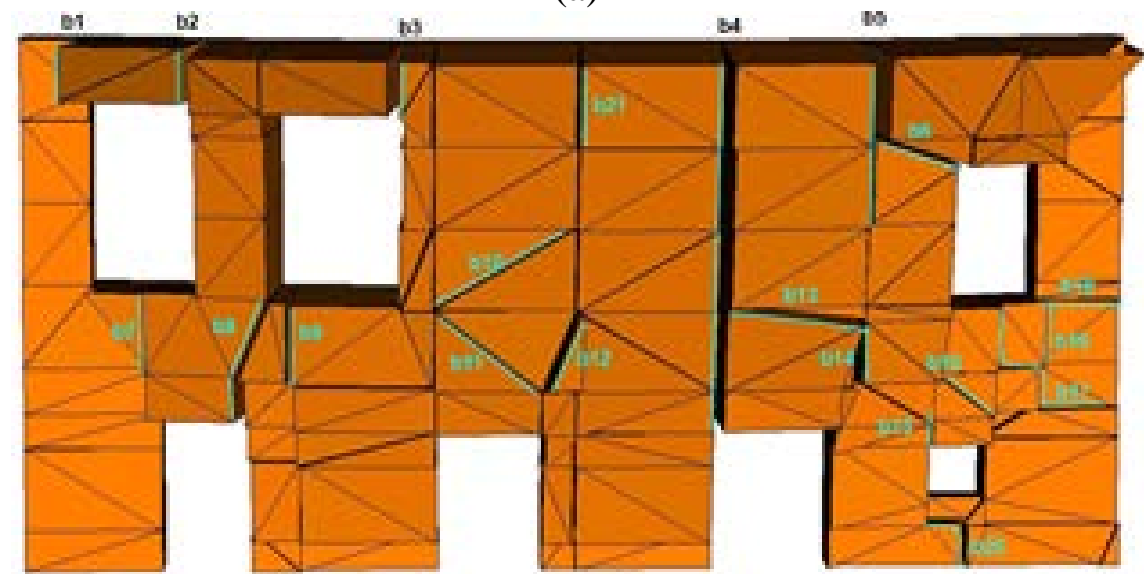

(b)

Figure 7: Typical Wall Collapse: (a) Heterogeneous and (b) Homogenous Model.

Form simulations results, it is found that the limit analysis load of the heterogeneous model with weak mortar equals $8.9 \%$ of the self-weight and the limit load of the homogeneous model is equal to $6.9 \%$ of the self-weight, which are again in reasonable agreement (20\% difference). The limit load of the heterogeneous model with strong mortar is equal to $34 \%$ of the self-weight, whereas the limit load of the homogeneous model is equal to $32 \%$ of the self-weight, again in reasonable agreement (10\% difference). It is also interesting to observe that the introduction of strong mortar significantly increases the limit load of the structure (almost four times). A synopsis of the failure loads found is summarized in Table 2.

\begin{tabular}{|c|c|c|c|}
\hline Joints & $\begin{array}{c}\text { Heterogeneous model } \\
\text { (\% of self-weight) }\end{array}$ & $\begin{array}{c}\text { Homogenous model } \\
\text { (\% of self-weight) }\end{array}$ & $\begin{array}{c}\text { Accuracy of } \\
\text { homogeneous model (\%) }\end{array}$ \\
\hline $\begin{array}{c}\text { Weak } \\
\text { mortar }\end{array}$ & 8.7 & 6.9 & 80 \\
\hline $\begin{array}{c}\text { Strong } \\
\text { mortar }\end{array}$ & 34.4 & 31.6 & 90 \\
\hline
\end{tabular}

Table 2. Comparison between heterogeneous and homogenized limit loads. 
Finally, it is noted that the analysis was performed on a standard PC Intel Pentium Dual $2.12 \mathrm{GHz}$ equipped with 3GB RAM. A comparison in terms of processing time, only for computing, indicates that the homogeneous model saves about $95 \%$ calculation time (30 vs. 600 seconds) and mesh preparation times (three vs. sixteen hours).

\section{Conclusions}

Non-linear tools often imply expensive computational costs, a good knowledge about non-linear processes and a large time to build the model and perform the analysis. This problem was addressed here by means of a geometrical investigation and homogenization of masonry. In particular, the behaviour at collapse of one perimeter wall belonging to the Guimarães castle in Portugal was investigated by means of a rigid-plastic homogenization procedure, accounting for the actual disposition of the blocks constituting the wall and the texture irregularity given by the variability of dimensions in the blocks.

After a simplification of the geometry and assuming mortar joints reduced to interfaces, homogenized masonry in- and out-of-plane strength domains were evaluated on a number of different representing elements of volume (RVEs) having different sizes and sampled on the walls of the castle.

By means of such strength domains, a homogenized limit analysis was carried out on a wall of the castle (Alcaçova) and results were compared with those provided by a standard heterogeneous discretization of the domain. The comparison, in presence of both good and weak mortar joints, have proved a satisfactory reliability of the homogenization proposed performed on different REVs with blocks having variable dimension.

\section{References}

[1] G. Milani, “3D upper bound limit analysis of multi-leaf masonry walls”, International Journal of Mechanical Sciences 50: 817-836, 2008

[2] P.B. Lourenço, "Computations of historical masonry constructions” Progress in Structural Engineering and Materials, 4(3), p. 301-319, 2002.

[3] J.G. Rots, "Numerical simulation of cracking in structural masonry" Heron, 36(2), p. 49-63, 1991.

[4] P.B. Lourenço, Milani, G. Tralli, A. Zucchini, "Analysis of masonry structures: review of and recent trends of homogenisation techniques" Canadian Journal of Civil Engineering, 34 (11), p. 1443-1457, 2007.

[5] P.B. Lourenço, J.G. Rots, "Multisurface interface model for the analysis of masonry structures” J. Engrg. Mech., ASCE, 123(7), p. 660-668, 1997.

[6] G. Milani, P.B. Lourenço, A. Tralli, "Homogenised limit analysis of masonry walls, Part I: failure surfaces” Computers \& Structures, 84, p. 166-180, 2006. 
[7] D.J. Sutcliffe, H.S. Yu, A.W. Page, "Lower bound limit analysis of unreinforced masonry shear walls” Computers \& Structures, 79, p. 1295-312, 2001.

[8] A.W. Page, "Biaxial failure criterion for brick masonry in the tension-tension range” International Masonry Journal, 1, p. 26-30, 1987.

[9] G. Milani, P.B. Lourenço, "A simplified homogenized limit analysis model for randomly assembled blocks out-of-plane loaded.” Computers \& Structures, 88, p. 690-717, 2010.

[10] G. Vasconcelos, P.B. Lourenço, C.A.S. Alves, J. Pamplona, “Experimental characterization of the tensile behaviour of granites" International Journal of Rock Mechanics and Mining Sciences, 45(2), 268-277, 2008.

[11] Y. Esquivel, "Characterization of the response of quasi-periodic masonry", MSC Thesis, University of Minho. Available from http://www.msc-sahc.org/, 2012.

[12] G. Milani, Y. Esquivel, P.B. Lourenço, B. Riveiro, D. Oliveira, Characterization of the response of quasi-periodic masonry: Geometrical investigation, homogenization and application to the Guimarães castle, Portugal. Under review, 2013.

[13] M. Dhanasekar, A.W. Page, P.W. Kleeman, "The failure of brick masonry under biaxial stresses” Proc. Instn. Civ. Engrs., Part 2, 79(2), p. 295-313, 1985. 